\title{
TREATMENT-RESISTANT EPILEPSY AND TREATMENT-RESISTANT SCHIZOPHRENIA; A REAL CHALLENGE FOR THE PSYCHIATRIC TEAM
}

\author{
Usama Bin Zubair, Eugene G Breen, Hamza Bin Zubair, Haytham Elhassan, Cathal P Coyne, Ibtihal Khair \\ Health Service Executive (HSE), Dublin Ireland
}

\begin{abstract}
Schizophrenia and epilepsy may exist together, but it is very rare to have a resistant form of both illnesses in one patient. We present a case report of a 49-year-old woman who was managed at our psychiatric facility suffering from treatment-resistant schizophrenia and epilepsy. She presented with suspiciousness, fearfulness and with a belief that people in the hostel wanted to harm her and were putting hair on her bed. She was also having recurrent seizures weekly due to her refractory epilepsy secondary to mesial temporal sclerosis. She was non-compliant with medication and refused surgical management of mesial temporal sclerosis. Whilst in the hospital was on five antiepileptic drugs prescribed by the neurology team and these control the seizures. Olanzapine and paliperidone depot was used for schizophrenia which had a partial response. Clozapine was not considered in view of her severe uncontrolled epilepsy. Concerns were raised regarding her capacity to decide about treatment options. The possibility of an organic cause for both schizophrenia and epilepsy were considered.
\end{abstract}

Keywords: Epilepsy, Schizophrenia, Treatment resistance.

How to Cite This Article: Zubair UB, Breen EG, Zubair HB, Elhassan H, Coyne CP, Khair I. Treatment-Resistant Epilepsy and Treatment-Resistant Schizophrenia; A Real Challenge for The Psychiatric Team. Pak Armed Forces Med J 2021; 71(5): 1906-1908. doi: https://doi.org/10.51253/pafmj.v71i5.4872

\footnotetext{
This is an Open Access article distributed under the terms of the Creative Commons Attribution License (https://creativecommons.org/licenses/by-nc/4.0/), which permits unrestricted use, distribution, and reproduction in any medium provided the original work is properly cited.
}

\section{INTRODUCTION}

Epilepsy has been related to the impaired electrical activity in the brain while schizophrenia has a neuro-chemical basis but they have been linked to each other in one way or the other as a psychotic phenomenon may be part of various types or phases of epilepsy and some of the schizophrenia medications may reduce seizure threshold or sometimes treatmentresistant schizophrenia may require electroconvulsive therapy as treatment. ${ }^{1-3}$ Structural lesions in the brain especially in the temporal lobe may be responsible for the production of both the seizure and psychotic symptoms and it is quite understandable that epilepsy and schizophrenic symptoms may be resistant to medical treatment if there is a lesion in the brain which needs a definitive surgical management. ${ }^{4}$

Various modalities have been used to manage treatment-resistant epilepsy. Multiple antiepileptic drugs (AEDs), brain stimulation techniques and surgical modalities all have been used in this regard. ${ }^{4}$ Similarly, treatment-resistant schizophrenia has been best managed with Clozapine. Electroconvulsive therapy has also been in practice for years now. When these two conditions co-exist that becomes a real challenge for the physicians as many AEDs may aggravate psychotic symptoms and Clozapine is notorious for

Correspondence: Dr Usama Bin Zubair, Registrar Psychiatrist, Health Service Executive Dublin Ireland

Received: 09 Jul 2020; revision received: 10 Nov 2020; accepted: 12 Nov 2020 reducing the seizure threshold. ${ }^{5}$ We present a case of treatment-resistant schizophrenia and treatment resistant epilepsy with underlying mesial temporal sclerosis.

\section{CASE REPORT}

A forty-nine old married female resident of Dublin, Ireland was admitted to the psychiatric unit as a voluntary patient due to suspiciousness, fearfulness and the belief that people around her wanted to harm her. These symptoms were suggestive of a relapse of her schizophrenia due to non-compliance. She had ongoing seizures with multiple presentations at the accident and emergency department. She was homeless and living in a hostel. She believed that people there were putting hair in her bed to monitor her and wanted to harm her. She also believed that the housing authority was against her. She has been non-compliant with her psychiatric medication and taking AEDs in a lesser quantity than prescribed. She was having generalized seizures every second week. She has been diagnosed with bilateral mesial temporal sclerosis and managed for epilepsy and schizophrenia for years. In 2017, she had an involuntary admission due to similar delusions and olfactory hallucinations after which she was put on Paliperidone depot due to non-compliance with oral medications. Neurologists have repeatedly given her information regarding surgical management of me-sial sclerosis which could be curative for her seizures, but she has declined. They have labelled her as high-risk of sudden unexplained death due to 
epilepsy (SUDEP). Capacity assessment of her understanding of epilepsy, psychosis and underlying organic condition has shown that she has capacity but is unwilling to proceed with surgical treatment.

Her mother died of cancer. She has had a distant relationship with her two sisters since she moved out of the home. Her brother was shot by her father at the age of 24 in self-defence. Her brother also suffered from schizophrenia. After that, the patient left her home and now has a distant relationship with her father. She stated that she had a normal birth and development and that she was told seizures started at the age of 18 months. No collateral history is available in this regard. She has been homeless living in hostels for years. She is a non-smoker, doesn't drink alcohol and denies any use of street drugs. She has no forensic history.

Her physical examination was unremarkable except for being overweight and having a scar on her forehead due to laceration after a fall during a seizure 3 months previously. Mental state examination revealed a middle-aged lady dressed appropriately with good rapport and eye contact. Her speech was normal in rate, rhythm and volume but pressured when the possibility of returning to a hostel was discussed. She insisted that she would live on the streets rather than return to a hostel. She intended to rent private accommodation. Her mood was subjectively and objectively euthymic. She was guarded and said everything was okay, but displayed delusions of reference and persecution on detailed inquiry. She did not hallucinate. She had no thoughts of self-harm or harming others. Her attention, concentration, judgment, long term and short-term memory were intact. When stabilized, her insight into her epilepsy was satisfactory and she was willing to take five AEDs but was ambivalent about the doses of AEDs. She declined assessment for definitive surgical management. Her insight into her schizophrenia was absent and she remained at high risk of non-compliance once discharged from the in-patient unit. The differential diagnosis included treatment-resistant schizophrenia with treatment-resistant epilepsy, organic psychosis secondary to mesial temporal sclerosis, interictal or postictal psychosis and AED induced psychosis.

All routine investigations (Blood CP, LFTs, RFTs, BSR and TSH) were normal. CT-brain scan was unremarkable. MRI brain revealed the bilateral mesial temporal sclerosis and EEG had slow background rhythm due to intermittent disturbance of right temporal func- tion. She refused the formal psychological assessment but the treating psychiatrist and occupational therapist had multiple assessments.

The neurology team titrated her AEDs and a combination of five AEDs achieved three months seizurefree status which was the first time she ever was seizure-free for such a duration. Her medicatios were Lamotrigine $200 \mathrm{mg}$ BD, Zonisamide $300 \mathrm{mg}$ nocte, Perapanel 10mg nocte, Clobazem 10mg BD and Eslicarbezipine $1600 \mathrm{mg}$. For her schizophrenia, her medications were Paliperidone depot $150 \mathrm{mg}$ every three months and Olanzapine $20 \mathrm{mg}$ nocte. She still had residual psychotic features. Her quality of life improved and she was availing of day and night leaves until she was discharged to the only available accommodation-a hostel. The psychiatry team manages her as an outpatient.

Despite the involvement of two psychiatric teams and two neurology teams in two different hospitals who agree on her management she continues to be non-compliant with medication with recurrent seizures and relapsing psychosis. Surgical intervention may not be a miracle cure but more willingness on her part could greatly improve her quality of life.

\section{DISCUSSION}

Puppala et al reported a similar case of a 48-yearold male who had mesial temporal sclerosis with seizures and psychosis. ${ }^{6}$ Two antiepileptics controlled the seizures but he was not fully seizure-free. Low dose olanzapine and trazodone made a marked improvement in his psychiatric and behavioural symptoms. Surgical treatment was not considered.

Marchetti et al reported a 47-year-old lady with refractory epilepsy and psychosis from the age of 12 years. Right temporal lobectomy cured both her psychotic and epileptic symptoms. ${ }^{7}$ This case supports the surgical management of refractory dual diagnoses.

Cascella et al published a comprehensive paper on the etiological link between schizophrenia and epilepsy. They highlighted the common neuroanatomical and neurochemical pathways which could lead to both of these illnesses. ${ }^{5}$ They suggested that these common pathways responsible for both the illnesses may predispose the individual having one to have the other at any point in time. ${ }^{5}$ Therefore, the coexistence of these neuropsychiatric illnesses in our case may be explained through the common underlying pathway in the temporal lobe.

Outcome data show that about two-thirds of patients are seizure-free in the first two to three years 
after surgery for mesial sclerosis. Surgical risks include a $0.24 \%$ chance of death, a $2 \%$ chance of serious permanent complications, and a $6 \%$ chance of transient complications. In comparison, the best medical therapies over a similar period yield a 5\% chance of becoming seizure-free and a $0.5-1.0 \%$ chance of death per year from epilepsy. Hence, surgery is a highly effective treatment for patients with medically refractory mesial sclerosis. ${ }^{8}$ This confirms that a lady at high risk for SUDEP and noncompliance to AEDs and antipsychotic medications may get a huge benefit from surgical management of medial sclerosis.

This lady's predicament is important for two reasons-the diagnoses and management. Whether schizophrenia with associated mesial sclerosis and epilepsy is an organic illness or not is a point of hot debate for decades. What is evident in some who have had surgery is its therapeutic effectiveness both for both illnesses. The issue around capacity, advocacy, and freedom to make what doctors think is the wrong decision is the nub of this lady's situation. We have not recruited a suitable advocate or next of kin to talk in simple English to this lady about the pros and cons of surgery. Unfortunately, we will have ample opportunity to do this on her next admission. Capacity legislation if enacted would help around her schizophrenia, compliance, and accommodation but would not apply to surgery since when stable she does have capacity.

Conflict of Interest: None.

\section{Authors' Contribution}

UBZ: Conception, case handling, writing of the manuscript, EGB: Conception, case handling, writing of the manuscript, HBZ: Conception, case handling, writing of the manuscript, HE: Conception, case handling, writing of the manuscript, $\mathrm{CPC}$ : Conception, case handling, writing of the manuscript, IK: Conception, case handling, writing of the manuscript.

\section{REFERENCES}

1. De Benedictis L, Dumais A, Nicole L, Grou C, Lesage AD. A patient with medication-resistant epilepsy featuring psychosensorial and psychotic symptoms presenting with significant functional improvement on psychotherapeutic treatment: a case report. J Med Case Rep 2013; 7(1): 259-265.

2. Jawaid H, Younus S, Mesiya H. Remission of psychosis in treatment-resistant schizophrenia following a seizure: a case report. Innov Clin Neurosci 2016; 13(5-6): 78-80.

3. Agrwal N, Mula M. Treatment of psychoses in patients with epilepsy: an update. Ther Adv Psychopharmacol 2019; 9(3): 1-10.

4. Moeller S, Kalkwarf N, Lücke C, Ortiz D, Jahn S, Forst C, et al. Achieving stable remission with maintenance electroconvulsive therapy in a patient with treatment-resistant schizophrenia: A case report. Medicine (Baltimore) 2017; 96(48): e8813.

5. Cascella NG, Schretlen DJ, Sawa A. Schizophrenia and epilepsy: is there a shared susceptibility?. Neurosci Res 2009; 63(4): 227235.

6. Puppala P, Thakore H, Edelman MJ. Case report of mesial temporal sclerosis with seizures and psychosis: an interface between psychiatry and neurology. Prim Care Companion J Clin Psych 2009; 11(1): 37-38.

7. Marchetti RL, Tavares AG, Gronich G, Fiore LA. Complete remission of epileptic psychosis after temporal lobectomy: case report. Arquivos de Neuro-Psiquiat 2001; 59(3B): 802-805.

8. Thom M, Mathern GW, Cross JH, Bertram EH. Mesial temporal lobe epilepsy: How do we improve surgical outcome? Ann Neurol 2010; 68(4): 424-434. 